\title{
World Journal of Use of 'T-tube' enterostomy in the management of emergency neonatal intestinal problems: a case series
}

\author{
Fazal Nouman Wahid (D), Abdelbasit E Ali
}

To cite: Wahid FN, Ali AE. Use of 'T-tube' enterostomy in the management of emergency neonatal intestinal problems: a case series. World Jnl Ped Surgery 2020;3:e000203. doi:10.1136/ wjps-2020-000203

Received 27 August 2020 Revised 22 October 2020 Accepted 23 0ctober 2020

Check for updates

(C) Author(s) (or their employer(s)) 2020. Re-use permitted under CC BY-NC. No commercial re-use. See rights and permissions. Published by BMJ.

Department of Pediatric Surgery, King Saud Medical City, Riyadh, Saudi Arabia

Correspondence to Dr Fazal Nouman Wahid; fazalnoman@hotmail.com
Emergency neonatal intestinal problems, such as necrotizing enterocolitis (NEC), spontaneous intestinal perforation (SIP), intestinal atresia, meconium cyst and meconium ileus, pose serious challenges for pediatric surgeons and neonatologists. Stoma creation and primary anastomosis have been used for decades with various advantages and disadvantages of each approach. ${ }^{1-4}$

Stoma creation is usually required in cases with generalized peritonitis and when perfusion and viability of distal parts of the intestine are questionable during laparotomy. In these life-threatening situations stoma formation results in improvement of survival. ${ }^{5}$ The main disadvantage of intestinal exteriorization is the need of another procedure for closure with prolonged hospitalization and repeated admissions. Other disadvantages include stomaassociated complications, such as high-output losses, electrolyte derangements, stenosis, skin excoriation, prolapse or retraction of the stoma, and parastomal protrusion or internal herniation through a mesenteric defect. ${ }^{1-4}$

Primary anastomosis should be performed in a neonate who is stable and has localized bowel disease. ${ }^{6} 7$ Potential problems with primary anastomosis are anastomotic leak, peritonitis, anastomotic stricture, stasis, and bacterial overgrowth. These are the main reasons why primary anastomosis is not often attempted in extremely low birthweight (ELBW) newborns. ${ }^{8}$

'T-tube' enterostomy is an alternative technique for a variety of such emergent intestinal problems. ${ }^{9-11}$ 'T-tube' combines the advantages of enterostomy (intestinal decompression, functioning low-output stoma) with those of primary anastomosis (restoration of intestinal continuity, preventing the need for a second operation, and avoiding stoma complications). We aim to assess the safety and effectiveness of 'T-tube' enterostomy in the management of emergency neonatal intestinal problems.
We treated neonates with emergency intestinal problems using 'T-tube' enterostomy between July 2016 and March 2020 in the Departments of Pediatric Surgery and Neonatology, King Saud Medical City, Riyadh, Saudi Arabia.

We included all premature and term neonates who underwent laparotomy for intestinal problems and had 'T-tube' placement during surgery. Demographic data collected included gestational age, weight, age at operation and final diagnosis. Postoperative surgical complications, outcome and follow-up information were retrieved.

Informed consent was obtained from parents. All the patients were operated by the same surgeon. The decision to use a 'T-tube' was made intraoperatively. This typically occurred in neonates that would otherwise require a proximal ostomy close to the duodenojejunal junction or in patients who underwent multiple bowel anastomoses. Prior to placement, the horizontal part of the 'T-tube' was trimmed to an appropriate length (figure 1) and was cut across the

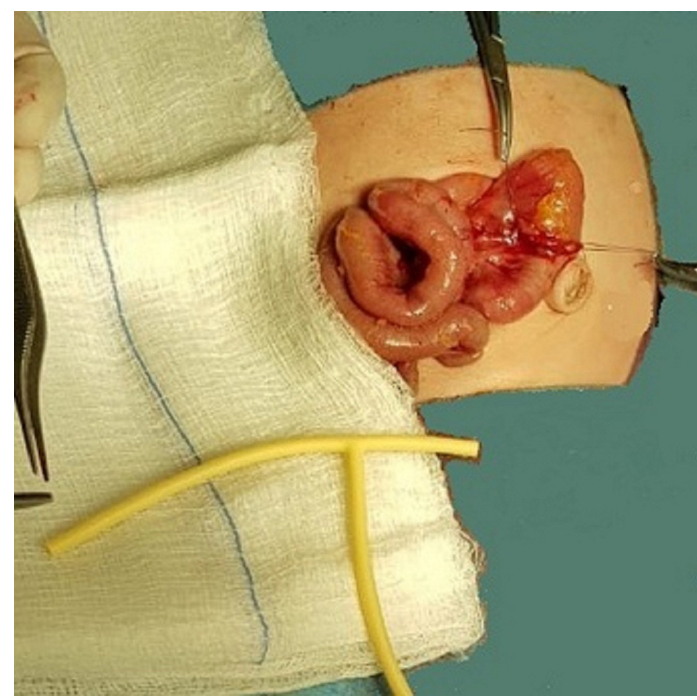

Figure 1 Horizontal part of 'T-tube' trimmed as needed. 


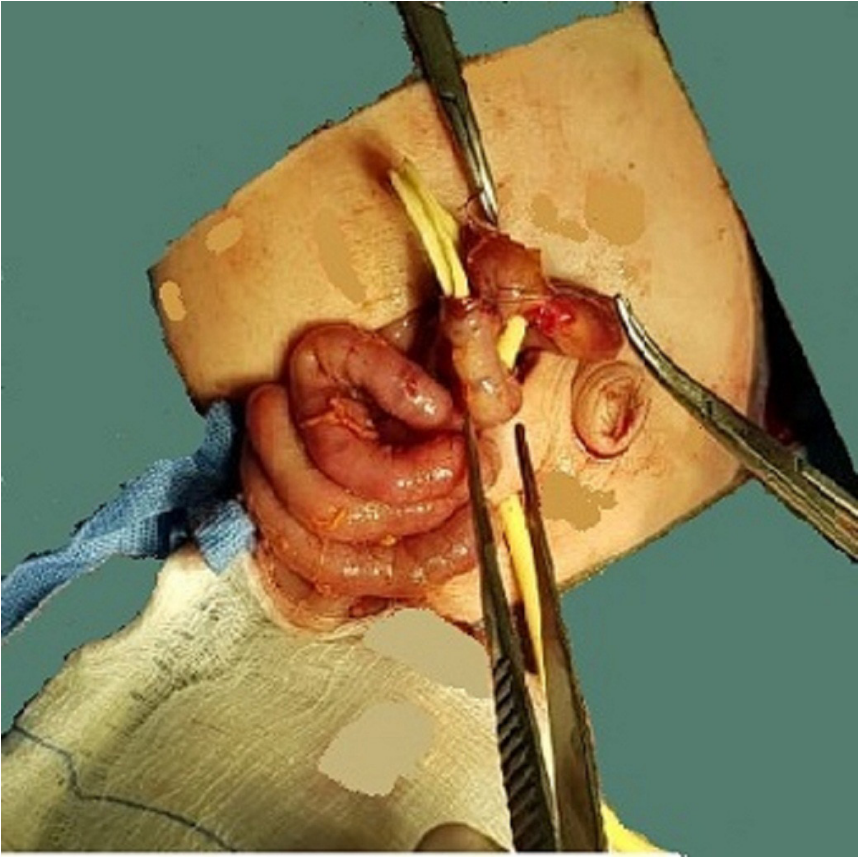

Figure 2 'T-tube' inserted into small bowel lumen prior to closing the anterior wall of the anastomosis.

lumen lengthwise to form a semicircle shape. 'T-tube' sizes 12-16 Fr were used. Prior to closing the anterior layer of anastomosis, the short limb and vertical part were inserted proximally where the vertical limb was retrieved through an enterotomy made $5 \mathrm{~cm}$ proximal to the anastomosis and brought out through a separate stab incision in the abdominal wall. This left the short arm of the horizontal part of the tube sliding in the proximal bowel lumen and the longer limb of the horizontal

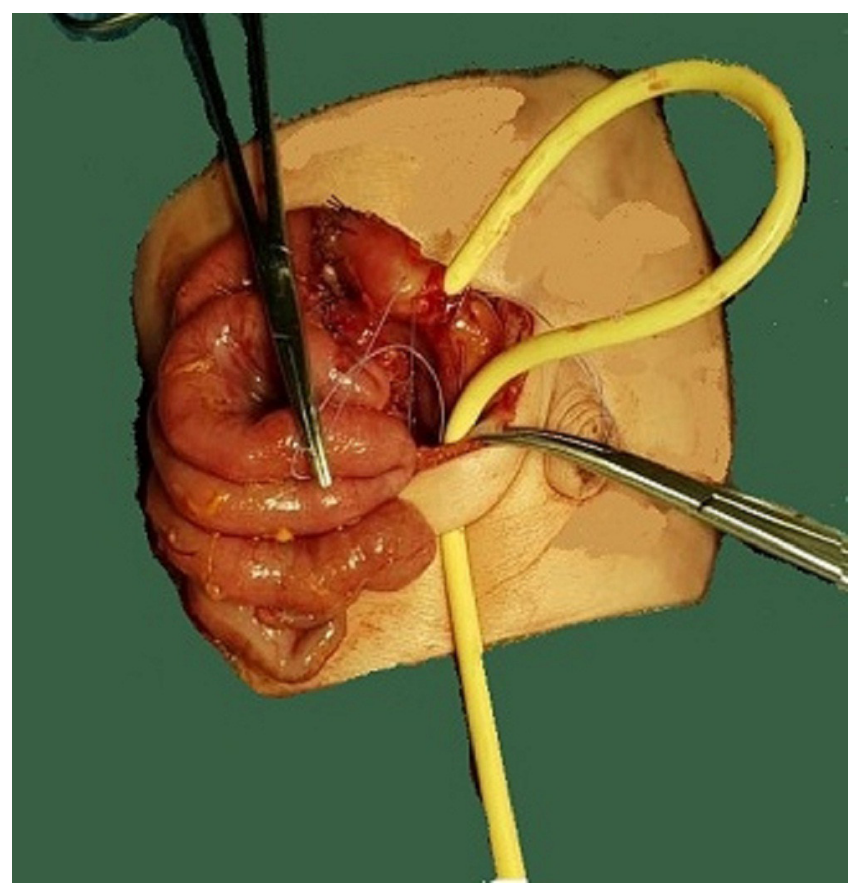

Figure 3 Vertical part of 'T-tube' retrieved through enterotomy and brought out through abdominal wall.

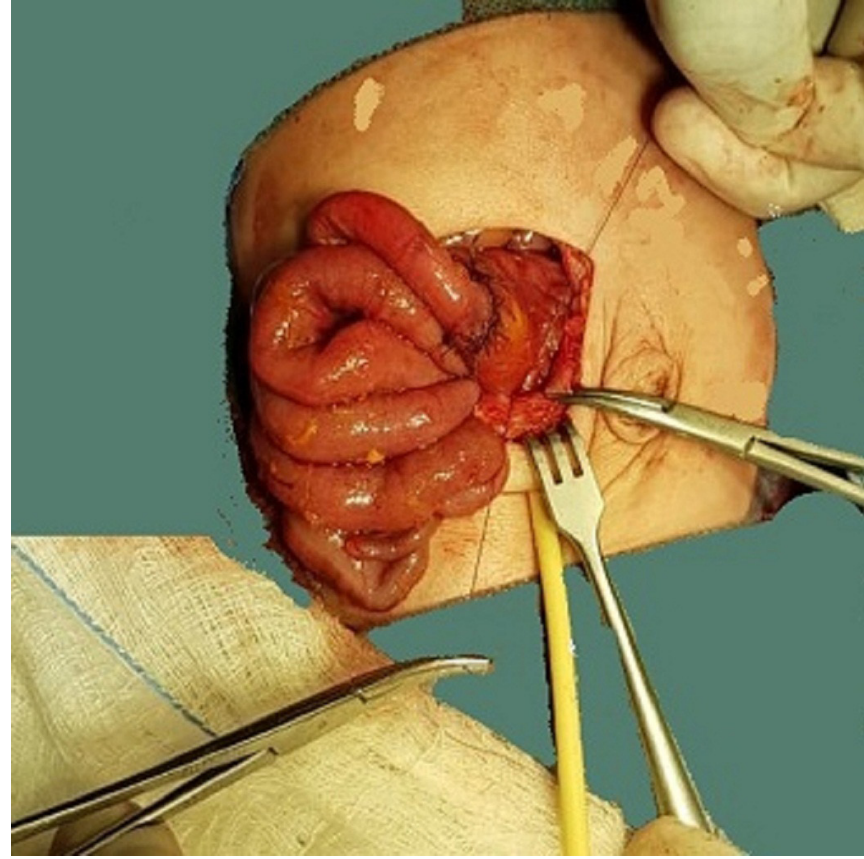

Figure 4 'T-tube' enterotomy site being sutured to abdominal wall from inside.

part placed as a transanastomotic stent in the distal bowel (figures 2 and 3). A purse-string suture was made around the enterotomy site, and the bowel was attached to the abdominal wall internally (figure 4) with the same suture to facilitate external drainage in case of leakage. A peritoneal drain may or may not have been inserted, depending on the degree of soiling. The external limb of the 'T-tube' was shortened and was left open for intestinal decompression; then the tube was gently flushed once daily with $2 \mathrm{ml}$ normal saline to prevent obstruction. A 'T-tube' contrast study may or may not have been done before removal of the 'T-tube'. A peritoneal drain was removed usually within $3-5$ days depending on drain output.

Fourteen neonates underwent laparotomy for different reasons and had 'T-tube' placement during surgery. The different etiologies were NEC with bowel perforation $(n=8)$, SIP $(n=1)$, jejunal atresia $(n=3)$, ileal stenosis with perforation $(\mathrm{n}=1)$, and meconium cyst (secondary to antenatal bowel perforation) $(\mathrm{n}=1)$.

In all cases the 'T-tube' was placed in the small intestine. The output from the 'T-tube' was minimal and mostly contained gases. The tube was gently flushed daily with $2 \mathrm{ml}$ of normal saline to keep it patent. Median gestational age of patients was 32 weeks [interquartile range $(\mathrm{IQR})=25.75-34.75]$. Median weight of neonates was $1.43 \mathrm{~kg}(\mathrm{IQR}=0.95-2.05)$. Median age at operation was 10 days $(\mathrm{IQR}=4-24.5)$. Nine $(64.28 \%)$ were males and five $(35.72 \%)$ were females. Median duration of 'T-tube' was 12 days $(\mathrm{IQR}=12-15)$.

Eight $(57 \%)$ of the 14 patients underwent contrast study through the 'T-tube' (figure 5) before its removal to confirm patency and integrity of the distal intestine. The peritoneal drain, if left during surgery, was removed 


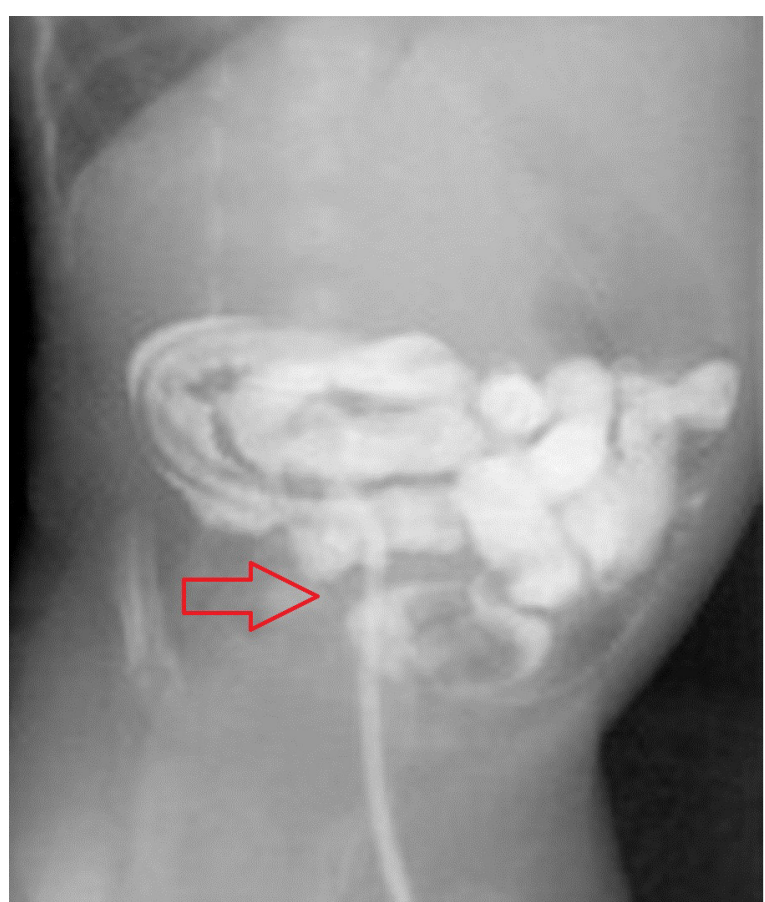

Figure 5 Postoperative contrast study via 'T-tube' indicated by arrow. Contrast study shows integrity and patency of intestine.

after 3-5 days. The 'T-tube' site usually closed spontaneously in 1-2 days. Feeding was started for almost all the patients within 1-2 days after removal of the 'T-tube'.

Three patients developed complications after the 'T-tube' placement. One patient developed pneumoperitoneum based on X-ray after 10 days postsurgery and had peritoneal drain placement. Bowel patency and integrity was confirmed with 'T-tube' contrast study (figure 5) after which the drain and 'T-tube' were removed. A second patient developed recurrent NEC and finally underwent laparotomy. The patient was found to have pneumatosis involving the whole colon with no ischemic changes, which suggested different pathology such as colitis. A diverting ileostomy was created, and the patient later underwent closure and was discharged home. A third patient developed enterocutaneous fistula after removal of the 'T-tube'. This baby was extremely premature with a weight of $720 \mathrm{~g}$, and the tube was left in place for 16 days, which might have contributed to the development of the enterocutaneous fistula. Later the patient had surgical closure of the fistula, which was uneventful.

Three deaths occurred in the series. These deaths were not related to the 'T-tube' but were caused by other problems, such as sepsis, respiratory failure, and pneumothorax. The first patient died 2 months after surgery because of respiratory failure. This patient had been tolerating feeding until that time. The second patient also died after 1 month from surgery because of central line-related sepsis and had a 'T-tube' contrast study, which was unremarkable. The third patient died after developing a pneumothorax from percutaneous central line placement. This patient also had a 'T-tube' study done earlier and it was otherwise unremarkable. Table 1 shows the summary of characteristics of all neonates and their outcomes.

The 'T-tube' enterostomy was first used in Texas Children's Hospital in 1959 but reported later. Since the first report of 'T-tube' enterostomy by Harberg et al in 1981, ${ }^{11}$ many reports described the use of 'T-tube' enterostomy in a variety of bowel problems. ${ }^{12-14}$ Most of the initial reports were focusing on use of 'T-tube' in the management of

\begin{tabular}{|c|c|c|c|c|c|c|c|}
\hline No & GA (wk) & Sex & Weight (kg) & Diagnosis & 'T-tube' days & Complication & Outcome \\
\hline 1 & 32 & $\mathrm{~F}$ & 1.9 & NEC & 12 & None & Discharged \\
\hline 2 & 30 & M & 1.5 & NEC & 12 & None & Discharged \\
\hline 3 & 32 & $M$ & 1.35 & NEC & 20 & $\begin{array}{l}\text { Pneumoperitoneum after } 10 \\
\text { days postsurgery }\end{array}$ & Discharged \\
\hline 4 & 25 & M & 0.72 & NEC & 16 & Enterocutaneous fistula & Discharged \\
\hline 5 & 32 & $M$ & 1.9 & NEC & 11 & Recurrent NEC & Discharged \\
\hline 6 & 24 & $\mathrm{~F}$ & 0.68 & NEC & 12 & None & Discharged \\
\hline 7 & 32 & M & 1.35 & NEC & 12 & None & Discharged \\
\hline 8 & 25 & M & 1.17 & NEC & 15 & None & Died \\
\hline 9 & 37 & M & 2.5 & Jejunal atresia & 12 & None & Discharged \\
\hline 10 & 37 & $\mathrm{~F}$ & 3 & Jejunal atresia & 13 & None & Discharged \\
\hline 11 & 34 & M & 1.8 & Jejunal atresia & 15 & None & Discharged \\
\hline 12 & 37 & $\mathrm{~F}$ & 2.7 & Meconium cyst & 11 & None & Discharged \\
\hline 13 & 26 & M & 0.78 & $\begin{array}{l}\text { Ileal stenosis } \\
\text { with perforation }\end{array}$ & 12 & None & Died \\
\hline 14 & 28 & $\mathrm{~F}$ & 1 & SIP & 12 & None & Died \\
\hline
\end{tabular}

F, female; M, male;GA, gestational age; NEC, necrotizing enterocolitis; SIP, spontaneous intestinal perforation. 
meconium ileus ${ }^{11-13}$; subsequent works described the use of this technique in various intestinal problems. ${ }^{9} 1014$

In 2007, Rygl et $a l^{10}$ showed the use of 'T-tube' enterostomy for intestinal perforations in five ELBW neonates with good survival and with no serious surgery-related complications. $^{10}$

Survival following the use of this technique was reported to be $71 \%$ in NEC, $83 \%$ in SIP, and $100 \%$ in meconium ileus. ${ }^{9}$ However, survival following resection and primary anastomosis in NEC has been reported to be $48 \% .{ }^{15}$ We did not have any patients with meconium ileus, probably owing to the rarity of this abnormality in our pediatric population. The survival rate for NEC in our small series of patients was $87.5 \%$. The better survival rate was probably due to our selection of patients when using 'T-tube' in patients with NEC. Though all the patients were diagnosed with stage III B as per modified Bell's staging, it was segmental NEC with bowel perforation that might have contributed to a better survival in our cohort.

In 2015, Mohsen et $a l^{16}$ reported the use of 'T-tube' in jejunal atresia with good results, comparable to our series. Our cohort also had three patients with jejunal atresia who had 'T-tube' and one of these patients even had multiple atresia with good outcome.

Almost all patients were started on feeds 1 day after the removal of the 'T-tube'. In some patients feeding was interrupted or held due to unrelated medical reasons. All infants that survived reached full feeds prior to being discharged home.

In conclusion, 'T-tube' enterostomy is an effective, safe and beneficial technique that provides an alternative to primary bowel anastomosis and stoma formation for treatment of selected cases of neonatal intestinal surgery.

\section{Twitter Fazal Nouman Wahid @dr_fazalnouman}

Acknowledgements We would like to thank Fazal Wasey who helped in editing the pictures.

Contributors FNW contributed to conceptualisation, data curation, investigation, project administration and manuscript writing. AEA participated in conceptualisation, investigation, manuscript writing and editing. All authors read and approved the final manuscript.

Funding The authors have not declared a specific grant for this research from any funding agency in the public, commercial or not-for-profit sectors.

Competing interests None declared.

Patient consent for publication Not required.
Ethics approval This study was conducted after approval from King Saud Medical City Institutional Review Board (H1RI-19-Sep19-02).

Provenance and peer review Not commissioned; externally peer reviewed.

Data availability statement All data relevant to the study are included in the article or uploaded as supplementary information. All data needed are available in the study.

Open access This is an open access article distributed in accordance with the Creative Commons Attribution Non Commercial (CC BY-NC 4.0) license, which permits others to distribute, remix, adapt, build upon this work non-commercially, and license their derivative works on different terms, provided the original work is properly cited, appropriate credit is given, any changes made indicated, and the use is non-commercial. See: http://creativecommons.org/licenses/by-nc/4.0/.

ORCID iD

Fazal Nouman Wahid http://orcid.org/0000-0003-3412-7213

\section{REFERENCES}

1 Wolf L, Gfroerer S, Fiegel H, et al. Complications of newborn enterostomies. World J Clin Cases 2018;6:1101-10.

2 al-Salem AH, Grant C, Khawaja S. Colostomy complications in infants and children. Int Surg 1992;77:164-6.

3 Rothstein FC, Halpin TC, Kliegman RJ, et al. Importance of early ileostomy closure to prevent chronic salt and water losses after necrotizing enterocolitis. Pediatrics 1982;70:249-53.

4 Nmadu PT. Complications of colostomy closure in Zaria, Nigeria: a report of 70 cases. Cent Afr J Med 1990;36:287-91.

5 Lin PW, Stoll BJ. Necrotising enterocolitis. Lancet 2006;368:1271-83.

6 Pumberger W, Mayr M, Kohlhauser C, et al. Spontaneous localized intestinal perforation in very-low-birth-weight infants: a distinct clinical entity different from necrotizing enterocolitis. J Am Coll Surg 2002;195:796-803

7 Fasoli L, Turi RA, Spitz L, et al. Necrotizing enterocolitis: extent of disease and surgical treatment. J Pediatr Surg 1999;34:1096-9.

8 Ramaswamy R, Hegab SM, Mugheri A, et al. Surgical treatment of necrotizing enterocolitis: single-centre experience from Saudi Arabia. Annals of Pediatric Surgery 2016;12:43-6.

9 Błaszczyński MI, Porzucek W, Becela P, et al. T-tube enterostomy in surgical management of emergency cases in neonate. Arch Perinat Med 2011;17:93-6.

10 Rygl M, Pycha K, Stranak Z, et al. T-tube ileostomy for intestinal perforation in extremely low birth weight neonates. Pediatr Surg Int 2007;23:685-8.

11 Harberg FJ, Senekjian EK, Pokorny WJ. Treatment of uncomplicated meconium ileus via T-tube ileostomy. J Pediatr Surg 1981;16:61-3.

12 Mak GZ, Harberg FJ, Hiatt P, et al. T-tube ileostomy for meconium ileus: four decades of experience. J Pediatr Surg 2000;35:349-52.

13 Millar AJ, Rode H, Cywes S. Management of uncomplicated meconium ileus with T tube ileostomy. Arch Dis Child 1988;63:309-10.

14 Al-Zaiem M, Al-Garni AF, Al-Maghrebi A, et al. Use of T-tube enterostomy in neonatal gastro-intestinal surgery. J Neonatal Surg 2016;5:46.

15 Cooper A, Ross AJ, O'Neill JA, et al. Resection with primary anastomosis for necrotizing enterocolitis: a contrasting view. $J$ Pediatr Surg 1988;23:64-8.

16 Mohsen R, Azita T, Alireza M. The role of routine transanastomotic T tube ostomy in jujunoileal atresia; A prospective,randomized study. Iran J Pediatr Surg 2015;1:5-10. 